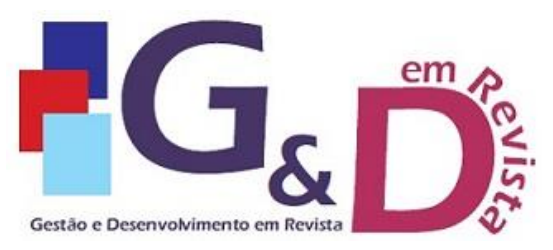

Gestão e Desenvolvimento em Revista V. 6, N. 1, jan-jun/2020, p. 3-14.

ISSN online: $2446-8738$

Artigo recebido em: 22/02/2019

Artigo aprovado em: 12/03/2020

\title{
GERENCIAMENTO DE RESÍDUOS DE SERVIÇOS DE SAÚDE EM UM HOSPITAL DO NORTE DO RIO GRANDE DO SUL
}

\author{
Alex Salomão \\ Graduação em Administração pela IMED Business School. \\ E-mail: alex.salomao001@gmail.com \\ Shalimar Gallon \\ Graduação, Mestrado e Doutorado em Administração. Atualmente é professora na IMED Business \\ School. E-mail: shalimargallon@gmail.com
}

Giana de Vargas Mores

Graduação em Ciências Econômicas. Mestrado e Doutorado em Agronegócios. Atualmente é professora na IMED Business School.

Email: gimores@gmail.com

\section{Resumo}

As práticas das instituições de assistência à saúde produzem quantidade significativa de resíduos hospitalares, os quais representam um problema para a saúde pública e o meio ambiente. Nesse contexto, o objetivo deste trabalho foi identificar como ocorre o gerenciamento de resíduos dos serviços de saúde em um hospital localizado ao norte do Rio Grande do Sul. Para tanto, realizou-se uma pesquisa qualitativa de caráter exploratório, a partir de entrevistas com base em um roteiro semiestruturado com doze profissionais ligados ao gerenciamento de resíduos hospitalares. Constatou-se que o hospital estudado emprega o plano de gerenciamento de resíduos de serviços de saúde e os empregados da instituição participam de forma ativa no gerenciamento, respeitando as diretrizes de segregação. A instituição conta com políticas de qualidade, comissão de redução de custos, água e energia, auxiliando na preservação do meio ambiente e na saúde humana.

Palavras-chave: Resíduos de Serviços de Saúde. Gerenciamento de Resíduos. Práticas de Gestão. Gestão Ambiental.

\begin{abstract}
The practices of health care institutions produce a significant amount of hospital waste, which represents a problem for public health and environment. In this context, the objective of this study was to identify how the waste management of health services occurs in a hospital located in the north of Rio Grande do Sul. A qualitative exploratory study was carried out, by means of interviews based on a semi-structured script with twelve employees involved in hospital waste management. It was verified that the hospital studied employs the health services of waste management plan and the institution's employees participate actively in the management, respecting the segregation guidelines. The institution counts on policies of quality, commission of reduction of costs, water and energy, helping in the preservation of the environment and in the human health.
\end{abstract}

Keywords: Waste from Health Services. Waste Management. Management Practices. Environmental Management. 


\section{INTRODUÇÃO}

A conscientização ambiental é o resultado da evolução do conhecimento e reflexo da humanidade em relação ao aproveitamento dos recursos naturais, a fim de minimizar a degradação do meio ambiente. Essas atividades incluem a destinação correta dos resíduos, a preservação de ecossistemas e dos recursos naturais, a diminuição do volume de resíduos gerados e o cumprimento da legislação vigente (BOTTI et al., 2015).

O contexto hospitalar destaca-se em função da periculosidade de alguns resíduos, pois exigem tratamento diferenciado (perigosos, patogênicos, patológicos, entre outras denominações). Nesse sentido, o manejo incorreto de Resíduos de Serviços de Saúde (RSS) pode comprometer a saúde humana e o meio ambiente (SANTOS; MEDEIROS; PORTELA, 2014). A destinação incorreta dos RSS pode estar associada à ausência de conhecimento da instituição sobre os malefícios gerados pela destinação desses resíduos (CAFURE; PATRIARCHA-GRACIOLLI, 2015).

No Brasil, a Resolução do Conselho Nacional do Meio Ambiente ํo 358, de 29 de abril de 2005, é responsável por regulamentar o tratamento e a disposição final dos RSS, pois esses resíduos são responsáveis por contaminar o solo. 0 descarte impróprio de RSS tem gerado danos ambientais capazes de aumentar os riscos e prejudicar os meios naturais e as condições de vida das atuais e futuras gerações (BRASIL, 2005a; BRASIL, 2006).

A proteção dos empregados e dos recursos naturais e a prevenção da saúde pública e do meio ambiente são fundamentais para a aplicação de medidas legais que, a partir do Plano de Gerenciamento de Resíduos de Serviços de Saúde (PGRSS), servem de instrumento norteador da gestão de resíduos (BORGES et al., 2017). Esse plano deve ser elaborado por um profissional de nível superior habilitado pelo seu conselho de classe (BRASIL, 2005b). O plano deve ser verificado constantemente e aperfeiçoado na busca de dados que sejam relevantes para se obter uma visão ampla e clara dos problemas durante o processo de criação (SCHNEIDER et al., 2013).

Os resíduos do sistema de saúde demandam atenção especial, assim como técnicas corretas de gerenciamento e manipulação adequada (RIZZON; NODARl; REIS, 2015). Por sua vez, os RSS requerem meios distintos para o manuseio e destinação final, pois as instituições de saúde têm o compromisso com a sociedade, bem como obrigações no descarte dos resíduos que geram (SEVERO, 2010).

Dados da Pesquisa Nacional de Demografia e Saúde de 2008 mostram que são coletadas cerca de nove mil toneladas de RSS por dia no Brasil (IBGE, 2010), sendo que os resíduos hospitalares são compostos entre 75 e $90 \%$ por resíduos comuns. Esses resíduos instituem um grave problema ao bem-estar das pessoas, podem gerar poluição e devastação de áreas ambientais e oportunizam a proliferação de patologias, o que exige uma gestão responsável do manejo à destinação final dos resíduos (BERTO; CZYKIEL; BARCELLOS, 2012; PASCHOALIN FILHO et al., 2014; BORELI; GODOY; KOZUSNY-ANDREANI, 2018). Diante da relevância desta temática, esse estudo tem por objetivo identificar como ocorre o gerenciamento de RSS em um hospital localizado ao norte do estado do Rio Grande do Sul. 


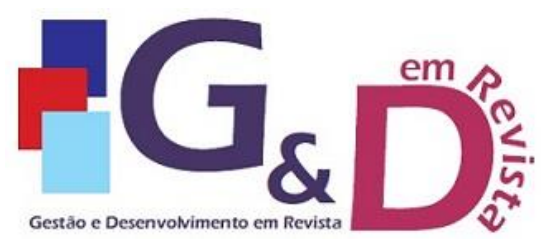

Gestão e Desenvolvimento em Revista

V. 6, N. 1, jan-jun/2020, p. 3-14.

ISSN online: $2446-8738$

Artigo recebido em: 22/02/2019

Artigo aprovado em: 12/03/2020

\section{REFERENCIAL TEÓRICO}

A economia mundial atravessa um momento de transformação em diversos setores (BORGES; RIELLA; JANISSEK, 2012), mas o setor ambiental chama atenção em função da disponibilidade dos recursos naturais. Portanto, é essencial que as instituições se amparem nos padrões ambientais, quer seja pela percepção dos gestores e da sua equipe de trabalho, quer seja pelas exigências do mercado, a fim de proporcionar atendimento com qualidade.

As discussões sobre a gestão ambiental foram intensificadas em meados do século $X X$, tendo atualmente um papel preponderante no âmbito das instituições de saúde por meio das práticas que auxiliam na qualidade de vida das pessoas que usufruem dos serviços. As instituições devem criar meios que proporcionem estratégias e inovações, favoreçam ações socioambientais e despertem em seus empregados uma consciência de reduzir as externalidades decorrentes do processo produtivo (RIBEIRO et al., 2012).

O Brasil possui leis avançadas em relação ao meio ambiente. A aprovação da Lei de Crimes Ambientais, ou Lei da Natureza (BRASIL, 1998), trouxe uma mudança para a sociedade, os órgãos ambientais e o Ministério Público, no qual obtiveram meios para punir quem não cumpria as leis inerentes ao meio ambiente (BRASIL, 2010). Conforme a Agência Nacional de Vigilância Sanitária (Anvisa), mediante a RDC no 306/2004, declara como RSS aqueles produzidos em algum serviço prestado à saúde, sanitária ou instituições, locais ambulatoriais de saúde, consultórios médicos, farmácias, laboratórios de análises e patológicas, bancos de sangue, clínicas veterinárias e consultórios odontológicos (BRASIL, 2004b).

De acordo com Bulcão e Albano (2010), os assuntos ambientais estão sendo incluídos ao setor de saúde, expondo a urgência de ultrapassar o modelo tradicional de atendimento no que diz respeito aos recursos disponíveis à saúde das pessoas. Nesse sentido, o PGRSS consiste em um grupo de processos elaborados, desde bases científicas e técnicas, normativas e regulares, na intenção de reduzir a formação de resíduos e destinar a um local seguro, de maneira efetiva, proporcionando segurança aos trabalhadores, cuidado à saúde humana, aos recursos naturais e ao meio ambiente (BRASIL, 2004a). Esse plano deve ser implantado respeitando as diretrizes de manejo e englobando as medidas de: segregação, acondicionamento, identificação, transporte, armazenamento intermediário e temporário, tratamento externo, coleta e transporte externo e destinação final (BRASIL, 2004b, grifos nossos).

O recolhimento dos RSS é feito a partir de critérios estabelecidos pelas legislações e da determinação estabelecida no PGRSS das instituições. Essas informações devem ser divulgadas a todos os envolvidos na área de atuação de serviços de saúde. As instituições, ao estabelecerem suas políticas de gerenciamento, devem explorar não apenas os aspectos internos que apontam a geração dos RSS, mas o agrupamento das relações externas que acabam impactando nos resultados (SCHNEIDER, 2004).

Faz-se necessário segregar e separar adequadamente os resíduos que são produzidos dentro dos hospitais. Conforme a aplicabilidade da Resolução da Diretoria Colegiada Anvisa no 206, de 23/2004, o manejo dos RSS nas fases de acondicionamento, identificação, armazenamento temporário e destinação final será tratado segundo a classificação dos resíduos, os quais são classificados de acordo com diferentes aspectos (Quadro 1). 
Quadro 1 - Classificação de resíduos de acordo com diferentes aspectos

\begin{tabular}{|l|l|}
\hline Classificação do resíduo & Conceito \\
\hline Origem & $\begin{array}{l}\text { Os resíduos são classificados considerando apenas a fonte } \\
\text { geradora. }\end{array}$ \\
\hline Periculosidade & $\begin{array}{l}\text { A classificação é realizada levando-se em conta o potencial de } \\
\text { riscos (biológicos, radiológicos e perfurocortantes) dos resíduos. }\end{array}$ \\
\hline Estado físico & $\begin{array}{l}\text { Os resíduos podem ser classificados como sólidos, } \\
\text { líquidos/efluentes, gasosos e pastosos. }\end{array}$ \\
\hline
\end{tabular}

Fonte: Adaptado de Política Nacional de Resíduos Sólidos (BRASIL, 2010).

Em estudos correlatos, Afonso et al. (2016) destacam que o destino incorreto dos resíduos em saúde representa forte ameaça ao meio ambiente e à saúde. Severo (2010) analisa a gestão ambiental nos hospitais no interior do estado do Rio Grande do Sul com base nas práticas de gestão e apoio à legislação vigente no Brasil. Como benefícios encontrados estão: a redução de resíduos, o uso de materiais ambientalmente corretos, a redução de custos, a eliminação de desperdícios e a criação de cunho ambiental. Os problemas encontrados estão ligados à conscientização e ao comprometimento de empregados e médicos, além do destino dos efluentes.

Silva e Rampelotto (2012) analisam o conhecimento e/ou comprometimento por parte das equipes de enfermagem das unidades intensivas, no processo de segregação dos resíduos sólidos. Sendo assim, conclui-se que ocorre a segregação de forma correta nas unidades intensivas de tratamento e os profissionais não consideram importante o processo de segregação, tendo em vista a importância para a enfermagem, devido à dificuldade do trabalho executado nas unidades intensivas.

\section{METODOLOGIA}

Esta pesquisa foi realizada em um hospital na cidade de Passo Fundo (estado do Rio Grande do Sul) em função da cidade ser reconhecida como um centro de referência em saúde para a região Norte do estado.

No âmbito deste trabalho, o hospital estudado foi fundado no ano de 1914, sendo a mais antiga instituição médico-hospitalar do município. É referência no norte do estado do Rio Grande do Sul para o Sistema Único de Saúde (SUS), pois

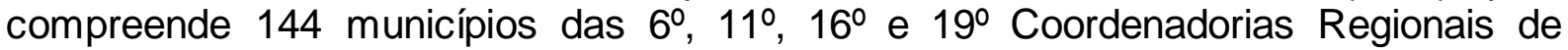
Saúde das cidades de Passo Fundo, Erechim, Palmeira das Missões e Frederico Westphalen, respectivamente, abrangendo aproximadamente 1.158 .00 habitantes. $O$ hospital destaca-se em procedimentos de alta complexidade em ortopedia e traumatologia, neurocirurgia, terapia substitutiva renal, oncologia e hemodinâmica.

Participaram do estudo doze profissionais (Quadro 2) que estão ligados ao gerenciamento de resíduos do hospital em questão. A técnica de escolha dos participantes foi por conveniência e snowball. A partir do primeiro contato, 0 enfermeiro responsável pelo controle de infecção do hospital (Entrevistado 1, nomeado como 'E1') fez as demais indicações. O número de respondentes foi definido a partir do critério de saturação. 
Quadro 2 - Descrição dos entrevistados

\begin{tabular}{|l|l|l|l|l|}
\hline Entrevistado & Sexo & Cargo & Formação \\
\hline E1 & Masculino & $\begin{array}{l}\text { Enfermeiro do Controle de } \\
\text { Infecção }\end{array}$ & Pós-graduado \\
\hline E2 & Feminino & Coordenadora da Qualidade & Ensino superior completo & \\
\hline E3 & Masculino & Biólogo & Ensino superior completo \\
\hline E4 & Masculino & $\begin{array}{l}\text { Técnico de Segurança do } \\
\text { Trabalho }\end{array}$ & $\begin{array}{l}\text { Técnico de Segurança do } \\
\text { Trabalho }\end{array}$ \\
\hline E5 & Feminino & Enfermeira de Unidade & Ensino superior completo & \\
\hline E6 & Feminino & Enfermeira de Unidade & Ensino superior completo \\
\hline E7 & Feminino & Enfermeira Radiologia & Ensino superior completo \\
\hline E8 & Feminino & Técnica de Enfermagem & Técnica de Enfermagem \\
\hline E9 & Feminino & $\begin{array}{l}\text { Técnica de Segurança do do } \\
\text { Trabalho }\end{array}$ & $\begin{array}{l}\text { Técnica de Segurança do do } \\
\text { Trabalho }\end{array}$ \\
\hline E10 & Masculino & Técnico em Radiologia & Técnico em Radiologia \\
\hline E11 & Feminino & Secretária Radiologia & Ensino médio completo \\
\hline E12 & Feminino & Supervisora de Compras & Ensino superior completo \\
\hline
\end{tabular}

Fonte: Elaborado pelos autores (2019).

Nas entrevistas, foi utilizado um roteiro semiestruturado para facilitar a conversação e a obtenção de dados. O instrumento de coleta de dados foi adaptado de Severo (2010). A coleta dos dados foi realizada durante os meses de setembro e outubro de 2018. As entrevistas foram presenciais e individuais, com a prévia autorização dos respondentes, assim como gravadas e transcritas (com a duração média de 30 minutos). Para a análise e interpretação dos dados, utilizou-se a análise qualitativa.

\section{APRESENTAÇÃO E ANÁLISE DOS RESULTADOS}

O hospital analisado possui um plano de gerenciamento de resíduos de serviços de saúde, no entanto, não possui um histórico da quantidade de resíduos gerados em seus processos. Em vista disso, as quantidades apresentadas foram fornecidas pelo E1 (enfermeiro do controle de infecção).

O PGRSS é um registro que ressalta e expõe as ações pertinentes ao manejo dos resíduos sólidos, notado de suas características e ameaças no âmbito das instituições, examinando os aspectos relacionados à identificação, segregação, acondicionamento, recolhimento, armazenamento, transporte, tratamento e disposição final (DUTRA; MONTEIRO, 2011).

A identificação dos resíduos deve ser feita por meio de sacos plásticos com coloração diferenciada e identificação dos recipientes onde se encontram, fornecendo assim, informações adequadas ao manejo e à destinação dos resíduos, conforme visualizado na Figura 1. 
Figura 1 - Lixeiras para descarte

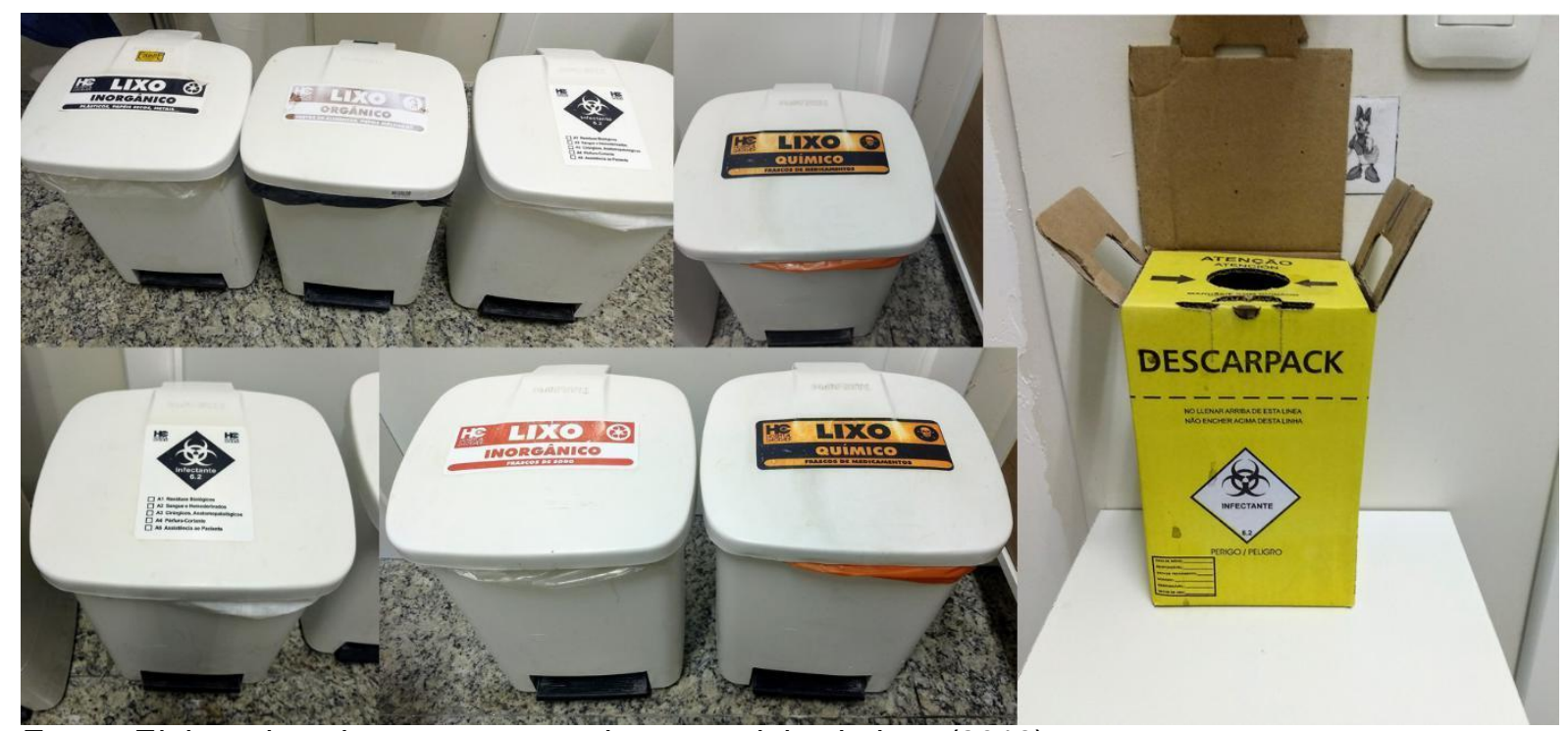

Fonte: Elaborada pelos autores com base na visita in loco (2018).

Conforme a Resolução do Conama n 358/2005, os sacos devem ser constituídos de material resistente a vazamentos, impermeável, baseado na NBR 9191/2000 da ABNT, respeitando os limites de peso de cada saco, sendo proibido o esvaziamento ou reaproveitamento. Os locais de disposição dos RSS devem ser identificados com os tipos de resíduos (Quadro 3).

Quadro 3 - Recipientes e cores utilizados para cada tipo de resíduo

\begin{tabular}{|l|l|l|}
\hline Recipiente & Cor & Tipo de resíduo \\
\hline Sacos & Transparente & Recicláveis (frascos de soros rígidos) \\
\hline Sacos & Vermelho & $\begin{array}{l}\text { Resíduos laboratoriais, restos de tecidos, produto de } \\
\text { fecundação sem vida, bolsas/recipientes contendo } \\
\text { sangue, membros amputados }\end{array}$ \\
\hline Sacos & Preto & Não recicláveis e orgânicos \\
\hline Sacos & Branco & $\begin{array}{l}\text { Infectante: órgãos ou tecidos, bolsas transfusionais } \\
\text { vazias }\end{array}$ \\
\hline Sacos & Laranja & Medicamentos vencidos \\
\hline Descarpack®/bombonas & - & Perfurocortantes \\
\hline Bombonas & - & Ampolas e frascos de medicamentos \\
\hline
\end{tabular}

Fonte: Adaptado do PGRSS do hospital pesquisado (2019).

Conforme as informações coletadas, o hospital analisado possui a segregação de resíduos. A segregação faz parte de um estágio fundamental para o êxito do gerenciamento dos resíduos (VIEIRA et al., 2016). Foi indicado que o hospital realiza a segregação de resíduos desde 2012 e que a média mensal de resíduos recicláveis gerados dentro da instituição é de $5.771 \mathrm{~kg}$ para papelões e 995 kg para plásticos.

Os gastos com o gerenciamento e o tratamento de RSS, nas instituições geradoras dos resíduos infectantes, acabam sendo altos em virtude da segregação que ocorre de maneira imprópria, descartando-se o resíduo comum juntamente com o infectante. Isso aumenta a quantidade de material contaminado e ocasiona um acréscimo nos custos, devido à destinação dos resíduos infectantes que são avaliados por quilos de material infectado. Nesse tocante, o E1 (enfermeiro do 
controle de infecção) relata que "melhorou a segregação correta e possibilidades de reciclagens de materiais".

O gerenciamento de resíduos, após a implantação dos programas de segregação, não teve variação de custos, pois não há dados que quantifiquem os anos anteriores, para que se possa fazer um comparativo, conforme relata a E2 (coordenadora de qualidade): "ainda não há dados registrados dos custos em anos anteriores para comparação". Sem esse comparativo, o hospital não mensura os ganhos econômicos que o programa traz para organização, o que pode implicar em percepção errônea do programa e vinculá-lo a uma imagem negativa de ser mais um custo para o hospital. Nesse sentido, Comunello, Trindade e Deimling (2017) mencionam que a questão ambiental é abordada rotineiramente dentro das instituições no sentido de diminuir os impactos ambientais causados pelos processos organizacionais, mas que também são necessárias ações que agreguem valor econômico e responsabilidade socioambiental.

Quanto à avaliação da segregação dos resíduos dentro do hospital estudado, pode-se constatar que há um profissional do Serviço de Controle de Infecção Hospitalar $(\mathrm{SCH})$ que realiza as auditorias de avaliação no que tange ao manuseio e à segregação, acondicionamento, transporte interno e externo, controle e reavaliação da desinfecção do local de armazenamento temporário. Porém, não possui indicadores que possam avaliar métodos de controle dentro da instituição. Juntamente com o responsável do $\mathrm{SCIH}$ são realizadas auditorias, respeitando 0 planejamento do checklist setorial, que ocorre a cada três meses nos postos de internações, como relata a E2 (coordenadora de qualidade): "a periodicidade é de acordo com o planejamento de checklist setorial e isso ocorre a cada três meses".

Os custos para armazenamento temporário na instituição são protuberantes, por se tratar de uma instituição filantrópica (CREMER et al., 2013). Na pergunta sobre os materiais armazenados sem previsão de destino, recebeu-se como resposta que não há materiais sem previsão de destino dentro da instituição.

Os entrevistados ressaltaram que existe treinamento na admissão de um empregado, independente da função a ser exercida, no qual se faz uma abordagem em relação à classificação dos resíduos, à segregação adequada dos resíduos e à segurança no trabalho. De acordo com a Resolução RDC 306 de 2004 da Anvisa, é determinado instruir os empregados das instituições de serviços de saúde para um manejo correto e gerenciamento dos resíduos.

O hospital estudado conta com três profissionais envolvidos no processo de recolhimento, armazenamento e transporte até o local destinado. Esses profissionais recebem treinamentos a cada seis meses, como relata a E2 (coordenadora de qualidade): "com os colaboradores ligados diretamente à coleta de resíduos isso ocorre a cada seis meses". Os demais profissionais, que desempenham as suas funções em outros setores da instituição, recebem treinamentos anualmente, conforme relata o E1 (enfermeiro do controle de infecção): "todos os colaboradores [recebem treinamento] uma vez ao ano".

Constatou-se que não ocorre frequentemente a participação dos médicos nos treinamentos ofertados pela instituição. Esses treinamentos são organizados pelo Serviço Especializado em Engenharia de Segurança e em Medicina do Trabalho (SESMT) e pelo Serviço de Controle de Infecções Hospitalares (SCH).

É importante destacar que a quantidade de resíduos infectantes coletados dentro da instituição, média mensal, foi de $10.870 \mathrm{~kg}$ dos resíduos de classe $\mathrm{A}$ (resíduos com possível presença de agentes biológicos) e $\mathrm{E}$ (materiais 
perfurocortantes) no ano de 2017, com um gasto mensal em torno de $R \$ 16.000,00$ com as coletas de material especial. Nesse caso, o gerenciamento dos resíduos não é avaliado.

O recolhimento interno do hospital em questão ocorre nas unidades geradoras dos resíduos. Nesta etapa do processo ocorre a retirada dos sacos dos respectivos recipientes que recebem as identificações de acordo com a Resolução Conama no 358/2005. Conforme Severo (2010), o PGRSS estabelece que o deslocamento consista em transportar os resíduos de maneira segura e ágil das fontes de criação até a área destinada para seu armazenamento.

O armazenamento externo fica em local com piso impermeável, conta com canaletas para contenção de líquidos e acesso restrito a pessoas que não são autorizadas, sendo que somente o pessoal que faz o manejo dispõe da chave de acesso. O recolhimento e o transporte externos dos resíduos de serviços de saúde são realizados por uma empresa especializada, com um contrato mensal para realizar estes serviços, atendendo a NBR 12.810 e a NBR 14.652 da ABNT (Quadro 4).

Quadro 4 - Programação para coleta de dos resíduos

\begin{tabular}{|l|l|l|l|l|l|}
\hline Resíduos & \multicolumn{2}{|l|}{ Coleta interna } & $\begin{array}{l}\text { Coleta } \\
\text { externa }\end{array}$ & Frequência & Horário \\
\hline $\begin{array}{l}\text { Grupo A } \\
\text { Infectante }\end{array}$ & $\begin{array}{l}\text { Expurgo - Abrigo } \\
\text { temporário }\end{array}$ & $\begin{array}{l}2 \\
\text { vezes/semana }\end{array}$ & $\begin{array}{l}\text { Terças e quintas- } \\
\text { feiras }\end{array}$ & $8 \mathrm{~h}$ \\
\hline Grupo B - Químico & $\begin{array}{l}\text { Expurgo - Abrigo } \\
\text { temporário }\end{array}$ & $\begin{array}{l}1 \\
\text { vezes/semana }\end{array}$ & Quintas-feiras & $8 \mathrm{~h}$ \\
\hline Grupo D - Comum & $\begin{array}{l}\text { Expurgo - Abrigo } \\
\text { temporário }\end{array}$ & Diariamente & Diariamente & $22 \mathrm{~h}$ \\
\hline $\begin{array}{l}\text { Grupo E E - Abrigo } \\
\text { Perfurocortante }\end{array}$ & $\begin{array}{l}\text { Expurgo } \\
\text { temporário }\end{array}$ & $\begin{array}{l}2 \\
\text { vezes/semana }\end{array}$ & $\begin{array}{l}\text { Terças e quintas- } \\
\text { feiras }\end{array}$ & $8 \mathrm{~h}$ \\
\hline
\end{tabular}

Fonte: Adaptado do PGRSS do hospital pesquisado (2019).

Em relação ao tratamento dos efluentes dentro do hospital estudado, constatou-se que são destinados à rede pública de coleta e tratamentos de esgoto, o qual pertence ao município de Passo Fundo. Todo o efluente gerado pela instituição estudada escoa pelas tubulações para os pontos de coleta municipal, no qual conta com uma caixa de escoamento de efluentes. $\mathrm{Na}$ chegada da estação de tratamento de efluentes, é feita a análise microbiológica, no qual a concessionária local (Companhia Rio-grandense de Saneamento) emite um laudo mensal e encaminha para a instituição.

De acordo com as informações coletadas no hospital em questão, a destinação final dos resíduos ocorre da seguinte forma: resíduos pertencentes à classe II - não perigosos serão dispostos para coleta pública e os resíduos da classe I - perigosos serão recolhidos e destinados pela empresa contratada. $O$ hospital estudado não possui incinerador próprio, sendo necessário manter contrato com uma empresa terceirizada para tratamento, empresa que mantém sua sede de coleta fora do município de Passo Fundo. De acordo com o E1 (enfermeiro do controle de infecção), "será realizada uma visita até o local, para uma possível avaliação do fornecedor, conforme as novas políticas da instituição".

Por todo exposto, a instituição conta com políticas de qualidade, comissão de redução de custos, água e energia, auxiliando na preservação do meio ambiente e na saúde humana. Assim, a gestão de resíduos hospitalares, juntamente com as 
questões ambientais, demonstra a importância que refletem na conjuntura social e no meio ambiente.

\section{CONSIDERAÇÕES FINAIS}

A partir da pesquisa realizada no hospital situado ao norte do $R S$, foi verificado que a instituição está preocupada com os resíduos gerados dentro dos setores, no entanto, os RSS requerem um cuidado especial, bem como as técnicas utilizadas para manejo. Juntamente com as políticas de qualidade, redução de custos e de recursos, como energia e água, resultarão em benefícios que serão vistos pela sociedade. Os problemas identificados da gestão ambiental dentro da instituição estão relacionados à falta de pessoal para gerenciar os resíduos, aprimorar e proporcionar um número maior de treinamentos direcionado aos resíduos hospitalares.

Conclui-se que o hospital estudado, por se tratar de uma instituição centenária e sendo referência para o município e região, deve seguir na adoção de práticas legais de gestão ambiental, respeitando as diretrizes vigentes no Brasil, para que possa manter e proporcionar um serviço de qualidade para a sociedade, assim como avançar nos processos da gestão ambiental. Ademais, que a gestão do hospital comece a analisar os dados gerados pelo plano de gerenciamento de RSS, a fim de perceber as vantagens econômicas desse processo.

Quanto às limitações encontradas no decorrer da pesquisa, destaca-se o número de pessoas capazes de responder ao instrumento de coleta de dados. Como sugestão para pesquisas futuras, indica-se selecionar hospitais de pequeno porte e de outras cidades para analisar como ocorre o plano de gerenciamento de RSS.

\section{REFERÊNCIAS}

AFONSO, T.; ZANON, M. A. G.; LOCATELLI, R. L.; AFONSO, B. P. D. Consciência ambiental, comportamento pró-ambiental e qualidade de gerenciamento de resíduos em serviços de saúde. Revista de Gestão Ambiental e Sustentabilidade, v. 5, n. 3, p. 106-119, 2016.

BERTO, D. N.; CZYKIEL, R.; BARCELLOS, M. D. Treinamentos sobre resíduos sólidos de serviços de saúde (RSSS) em hospitais de Porto Alegre/RS na percepção de profissionais atuantes. Revista de Gestão em Sistemas de Saúde, v. 1, n. 2, p. 41-62, 2012.

BORELI, D.; GODOY, S. R.; KOZUSNY-ANDREANI, D. I. Gestão de resíduos sólidos infectantes em uma unidade hospitalar. Revista Nucleus, v. 15, n. 1, p. 257268, 2018.

BORGES, N. C. F.; ALVES, M. A.; FIGUEIREDO, G. L. A.; CASTRO, G. G. Planos de gerenciamento de resíduos de serviços de saúde: uma análise sobre conhecimento e qualificação dos colaboradores. Revista Brasileira de Geografia Médica e da Saúde, v. 13, n. 24, p. 14-23, 2017. 
BORGES, S. M.; RIELLA, G. H.; JANISSEK, R. P. Demandas da gestão de resíduos ambientais, econômicos e tecnológicos: Uma ferramenta de otimização. Revista de Gestão Ambiental e Sustentabilidade, v. 1, n. 2, p. 143-157, 2012.

BOTTI, S. C. C. F.; IRAZUSTA, S. P.; SILVA, M. L. P.; TEIXEIRA, E. P. Análise comparativa da comunicação ambiental de três grandes hospitais do município de São Paulo-SP. Revista Insiet, v. 2, n. 1, p. 88-108, 2015.

BRASIL. Lei no 9.605, de 12 de fevereiro de 1998. Dispõe sobre as sanções penais e administrativas derivadas de condutas e atividades lesivas ao meio ambiente, e dá outras providências. $1998 . \quad$ Disponível em: <//www.planalto.gov.br/ccivil_03/leis/L9605.htm>. Acesso em: 12 dez. 2018.

BRASIL. Resolução da Diretoria Colegiada - RDC no 206, de 23 de agosto e 2004. Publicada no DOU no 163, de 24 de agosto de 2004. Anvisa, 2004a. Disponível em: <http://portal.anvisa.gov.br/documents/10181/2718376/RDC_206_2004_COMP.pdf/2 4e5c885-b6ee-4882-bc74-39b0c00fc48b?version=1.0>. Acesso em: 04 dez. 2018.

BRASIL. Resolução da Diretoria Colegiada - RDC no 306, de 7 de dezembro de 2004. Dispõe sobre o Regulamento Técnico para o gerenciamento de resíduos de serviços de saúde. Anvisa, 2004b. Disponível em: <http://portal.anvisa.gov.br/documents/33880/2568070/res0306_07_12_2004.pdf/95 eac67 8-d441-4033-a5ab-f0276d56aaa6>. Acesso em: 10 dez. 2018.

BRASIL. Resolução Conama 357, de 17 de março de 2005. Conselho Nacional de Meio Ambiente. 2005a. Disponível em: <http://www.mma.gov.br/port/conama/res/res05/res35705.pdf>. Acesso em: 21 nov. 2018.

BRASIL. Resolução Conama no 358, de 29 de abril de 2005. Publicada no DOU n. 84, de 4 de maio de 2005, seção 1. 2005b. Disponível em: <http://www2.mma.gov.br/port/conama/legiabre.cfm?codlegi=462>. Acesso em: 23 nov. 2018.

BRASIL. Resolução Anvisa RDC $n^{\circ}$ 156, de 11 de agosto de 2006. Dispõe sobre o registro, rotulagem e reprocessamento de produtos médicos, e dá outras providências. $2006 . \quad$ Disponível em: <http://bvsms.saude.gov.br/bvs/saudelegis/anvisa/2014/rdc0028_14_05_2014.pdf>. Acesso em: 22 nov. 2018.

BRASIL. Lei no 12.305 de 02 de agosto de 2010. Institui a política nacional de resíduos sólidos; altera a Lei no 9.605, de 12 de fevereiro de 1998; e dá outras providências. 2010. Disponível em: <http://www.planalto.gov.br/ccivil_03/_Ato20072010/2010/Lei/L12305. htm>. Acesso em: 09 dez. 2018.

BULCÃO, G. L.; ALBANO, A. H. O gerenciamento de resíduos sólidos na região metropolitana II do estado do Rio de Janeiro. Revista de Gestão Social e Ambiental, v. 4, v. 2, p. 75-85, 2010. 
CAFURE, V. A.; PATRIARCHA-GRACIOLLI, S. R. Os resíduos de serviço de saúde e seus impactos ambientais: uma revisão bibliográfica. Interações, v. 16, n. 2, p. 301-314, 2015.

COMUNELLO, F.; TRINDADE, L. L.; DEIMLING, M. F. (2017). Modelo para avaliação ambiental em sistemas produtivos industriais: um estudo de caso em uma indústria de transformação de plástico. Revista de Gestão Ambiental e Sustentabilidade, v. 6, n. 1, p. 87-106, 2017.

CREMER, E.; VITTA, A.; SIMEÃO, S. F. A. P.; CONTI, M. H. S.; GALDINO, M. J. Q.; BORGATO, M. H.; MARTA, S. N.; GATTI, M. A. N. Saúde do trabalhador e riscos de resíduo no ambiente hospitalar segundo a normal regulamentadora 32 . Revista Salusvita, v. 32, n. 3, p. 265-284, 2013.

DUTRA, L. M. A.; MONTEIRO, P. S. Gerenciamento de resíduos sólidos em um hospital de ensino em Brasília. Com. Ciências Saúde, v. 22, n. 4, p. 305-314, 2011.

IBGE. Censo 2010. Brasília: IBGE, 2010. Disponível em: <https://censo2010.ibge.gov.br>. Acesso em: 10 nov. 2018.

PASCHOALIN FILHO, A. J.; SILVEIRA, F. F.; LUZ, E. G.; OLIVEIRA, R. B. Comparação entre as massas de resíduos sólidos urbanos coletadas na cidade de São Paulo por meio de coleta seletiva e domiciliar. Revista de Gestão Ambiental e Sustentabilidade, v. 3, n. 3, 19-33, 2014.

RIBEIRO, M. B. S.; UHLMANN, V. O; PFITSCHER, E. D.; RAMOS, C. M. R. Análise da gestão ambiental: estudo em dois hospitais da Grande Florianópolis. Rev. Elet. em Gestão, Educação e Tecnologia Ambiental, v. 8, n. 8, p. 1829-1850, 2012.

SANTOS, T. R.; MEDEIROS, E. M. F.; PORTELA, R. A. (2014). Acondicionamento dos resíduos sólidos dos serviços de saúde nas unidades básicas de saúde (UBS) do município de Caicó/RN. Revista Brasileira de Geografia Médica e da Saúde, v. 10, n. 18, 46-57, 2014.

SCHNEIDER, V. E. Sistema de gerenciamento de resíduos sólidos de serviços de saúde: contribuição aos estudos das variáveis que interferem no processo de implantação, monitoramentos e custos decorrentes. Tese (Doutorado em Engenharia de Recursos Hídricos e Saneamento Ambiental) - Universidade Federal do Rio Grande do Sul, Porto Alegre, 2004.

SCHNEIDER, V. E.; STEDILE, N. L. R.; BIGOLIN, M.; PAIZ, J. C. Sistemas de informações gerenciais (SIG): ferramenta de monitoramento do gerenciamento de resíduos de serviços de saúde (RSS) e de custos de tratamento. Revista de Gestão Ambiental e Sustentabilidade, v. 2, n. 1, p. 166-188, 2013.

SEVERO, E. A. análise do gerenciamento ambiental nos hospitais de Caxias do Sul - RS. Dissertação (Mestrado em Administração) - Universidade de Caxias do Sul, Caxias do Sul, 2010. 

V. 6, N. 1, jan-jun/2020, p. 3-14.

ISSN online: $2446-8738$

Artigo recebido em: 22/02/2019

Artigo aprovado em: 12/03/2020

SILVA, N. M.; RAMPELOTTO, E. M. Segregação dos resíduos sólidos hospitalares. Revista Monografias Ambientais, v. 5, n. 5, p. 1174-1183, 2012.

VIEIRA, C. S. M.; NAZARI, M. T.; GONÇALVES, C. G.; CORRÊA, L. B. Manejo de resíduos de serviços de saúde em uma unidade básica de saúde vinculada a uma instituição de ensino superior. Ciência e Natura, v. 38, n. 3, p. 1580-1589, 2016. 